\title{
INFLUÊNCIA DO CAPITAL PSICOLÓGICO NA INTENÇÃO DE ROTATIVIDADE DE AUDITORES INDEPENDENTES
}

\author{
Mara Vogt 1 \\ Cleyson Marcos 2 \\ Paulo Roberto da Cunha ${ }^{3}$
}

- Artigo recebido em: 04/02/2020 -- Artigo aceito em: 12/07/2020 -.- Segunda versão aceita em: 15/07/2021

\section{RESUMO}

Este estudo objetiva verificar a influência do capital psicológico na intenção de rotatividade de auditores independentes. Realizou-se uma pesquisa descritiva, de levantamento e com abordagem quantitativa. A amostra foi composta por 166 auditores independentes que responderam devidamente o questionário proposto. O constructo do Capital Psicológico no Trabalho é constituído de quatro dimensões: autoeficácia, otimismo, esperança e resiliência. Já o constructo relacionado a Intenção de Rotatividade no Trabalho é constituído de uma escala constituída de três questões que avaliam o grau em que um indivíduo elabora planos para sair da firma. Para a análise dos dados utilizou-se a análise descritiva de frequências e a técnica estatística regressão logística multinomial. Os resultados indicam uma relação direta entre o médio otimismo dos auditores e a média e alta intenção de rotatividade (turnover). Ademais, uma relação inversa entre a média resiliência e a alta intenção de rotatividade. O estudo também buscou compreender as percepções dos auditores relacionadas ao sexo. Os auditores com cargo de sócios apresentam menor intenção média de rotatividade, o que pode ser explicado pelo tempo que atuam na firma de auditoria e o cargo que possuem, que lhes oferece mais estabilidade e garantia de permanecer na firma de auditoria. As evidências do estudo indicam influência do capital psicológico na intenção de rotatividade de auditores independentes a partir das dimensões otimismo e resiliência. Outra constatação relevante é que

\footnotetext{
1 Doutora em Ciências Contábeis e Administração pela Universidade Regional de Blumenau (FURB). Professora da graduação em Ciências Contábeis e Administração da Universidade Federal de Santa Catarina (UFSC). Endereço: Rua Antônio da Veiga, 140, sala D202, Victor Konder, CEP: 89012-900 - Blumenau / SC - Brasil. Telefone: (47) 3321-0565. E-mail: maravogtcco@gmail.com.

https://orcid.org/0000-0002-3951-4637

2 Mestre em Ciências Contábeis pela Universidade Regional de Blumenau (FURB). Professor na Faculdade Capivari (FUCAP). Endereço: Rua Antônio da Veiga, 140, sala D202, Victor Konder, CEP: 89012-900 - Blumenau / SC - Brasil. E-mail: cleyson.contabilidade@gmail.com.

3 Doutor em Ciências Contábeis e Administração pela Universidade Regional de Blumenau (FURB). Professor do Programa de Pós-Graduação em Ciências Contábeis da Universidade Regional de Blumenau (FURB) e da graduação em Ciências Contábeis da Universidade Estadual de Santa Catarina (UDESC). Endereço: Rua Antônio da Veiga, 140, sala D202, Victor Konder, CEP: 89012-900 - Blumenau / SC - Brasil. E-mail: pauloccsa@furb.br.
}

https://orcid.org/0000-0001-5805-9329

Editora responsável pela aprovação do artigo: Drª Bruna Camargos Avelino Editora responsável pela edição do artigo: $\mathrm{Dr}^{\mathrm{a}}$. Bruna Camargos Avelino 
para as firmas de auditoria, o Capital Psicológico no Trabalho pode contribuir na gestão dos auditores, no que concerne a identificação e o monitoramento da intenção de rotatividade.

Palavras-Chave: Capital Psicológico no Trabalho. Intenção de Rotatividade. Auditores Independentes.

\title{
INFLUENCE OF PSYCHOLOGICAL CAPITAL ON TURNOVER INTENTION OF THE INDEPENDENT AUDITORS
}

\begin{abstract}
This study aims to verify the influence of psychological capital on the turnover intention of independent auditors. A descriptive survey and quantitative approach was carried out. The sample consisted of 166 independent auditors who duly answered the proposed questionnaire. The Psychological Capital at Work construct consists of four dimensions: self-efficacy, optimism, hope and resilience. The construct related to the Intention to Turnover at Work, on the other hand, consists of a scale consisting of three questions that assess the degree to which an individual makes plans to leave the firm. For data analysis, descriptive frequency analysis and the multinomial logistic regression statistical technique were used. The results indicate a direct relationship between the auditors' medium optimism and the medium and high turnover intention. Furthermore, an inverse relationship between medium resilience and high turnover intent. The study also sought to understand the auditors' perceptions related to sex. The auditors with partner positions have a lower average turnover intention, which can be explained by the time they work in the audit firm and the position they have, which offers them more stability and guarantee to remain in the audit firm. The evidence from the study indicates the influence of psychological capital on the intention of turnover independent auditors based on the dimensions of optimism and resilience. Another relevant finding is that for audit firms, Psychological Capital at Work can contribute to the management of auditors, with regard to the identification and monitoring of the turnover intention.
\end{abstract}

Keywords: Psychological Capital at Work. Rotation Intention. Independent Auditors.

\section{INTRODUÇÃO}

O cenário atual demonstra que há uma crescente preocupação com as pessoas dentro das organizações (Hammes, Santos \& Melim, 2016). Ainda de acordo com os autores, considerando que as pessoas são o ativo mais importante para as empresas, estratégias para atrair e reter essas pessoas, evitando um alto índice de rotatividade, tornando o processo produtivo e aumentando ainda mais a competitividade no mercado, são necessárias. Contudo, Zhen e Mansor (2020) frisam que, embora os empregadores tenham buscado uma variedade de estratégias para reter funcionários qualificados, a taxa de rotatividade ainda permanece alta na grande maioria das empresas em todo o mundo. 
A rotatividade de empregados (turnover) é considerada um problema para muitas organizações, em função dos custos para o empregador, particularmente nos trabalhos que requerem o oferecimento de extensivo treinamento aos seus profissionais. O problema dos custos de reposição de pessoal foi um dos fatores que estimulou o desenvolvimento de pesquisas voltadas para a análise da rotatividade (Campos \& Malik, 2008). Estes custos de reposição de mão de obra perpassam o processo de seleção, treinamento inicial e contínuo desses profissionais, além da perda de conhecimento, de capital intelectual, de inteligência e controle de processos (Assis, 2010).

Da mesma forma, Hammes et al. (2016) concordam com a ideia anteriormente exposta ao aduzir que, além da perda de capital humano, a rotatividade se torna onerosa em termos de custos administrativos, treinamentos e custos de recrutamento de novos funcionários. Isso pode resultar em um efeito negativo no aspecto econômico-financeiro, além de afetar a qualidade da auditoria, seja esta externa ou interna (Hammes et al., 2016). Nesse sentido, subjacente à independência do auditor tem-se a obrigatoriedade da sua rotatividade na empresa que divide opiniões (Ribeiro, 2019).

Segundo Ribeiro (2019), alguns autores defendem que a rotatividade de auditores aumenta a qualidade da auditoria e assegura maior independência por parte do auditor para execucão do seu trabalho. A Comissão de Valores Mobiliários (CVM) passou a exigir das empresas brasileiras de capital aberto, que promovessem a rotatividade das firmas as quais analisam as suas demonstrações contábeis, com o intuito de assegurar a independência das firmas de auditoria (Martinez, 2010). Mas o fato é que no Brasil ainda não se conhece o efeito prático e real desse rodízio de auditoria e existem questões altamente controversas (Martinez, 2010). Por outro lado, Martinez (2010) e Ribeiro (2019) afirmam que tem os que defendem que a rotatividade só traz problemas e apresenta pontos negativos, como elevados custos, maiores honorários de auditoria e sem benefícios comprovados (custo-benefício). Também é preciso ter em mente a necessidade ou sugestão de que haja rotatividade em firmas de auditoria, advêm das próprias firmas ou órgãos superiores. Já a intenção de rotatividade parte do próprio auditor.

Beuren, Ribeiro e Silva (2019) aduzem que, embora a rotatividade crescente de auditores seja considerada um movimento normal, é importante considerar os atributos esperados dessa mão de obra especializada. Até porque, segundo os autores, a percepção de (in)justiça dos auditores em relação aos processos decisórios que Ihes dizem respeito nas firmas de auditoria pode impactar sua confiança, comprometimento, desempenho, bem como, na rotatividade. Já é sabido que o trabalho do auditor é considerado estressante, caracterizado por uma carga de trabalho e muitos prazos (curtos), o que pode resultar em desgaste e insatisfação com o trabalho e, por sua vez, maior intenção de rotatividade (Yuen, Law, Lu \& Guan). Por conta disso, atualmente tem-se uma alta taxa de rotatividade que alarma as empresas de auditoria (Yuen et al., 2013).

Todo esse contexto pode ser identificado mediante as experiências que os auditores independentes vivenciam no ambiente pessoal e de trabalho. 0 trabalho de campo do auditor proporciona ao mesmo tempo uma diversidade de experiências, inserindo este profissional em um ambiente de aprendizado e evolução constante. Entretanto, o auditor também passa por diferentes desafios diários, como a necessidade de manter-se atualizado frente a um leque de 
normas e legislações, o atendimento de requisitos advindo de órgãos reguladores e fiscalizadores, as constantes viagens e horas extras realizadas, as disputas de redução de honorários de auditoria que por vezes podem comprometer a aplicação de procedimentos de auditoria na busca de evidências, a autocobrança pela qualidade da auditoria realizada.

Sendo assim, tal realidade pode fazer com que o auditor reflita sobre o seu desempenho, podendo levar a intenção de saída da firma de auditoria (turnover). Logo, é primordial compreender os fatores que levam trabalhadores a deixarem a empresa para evitar as possíveis perdas com a rotatividade (Kazi \& Zadeh, 2011). Para as firmas de auditoria, torna-se prudente ter uma gestão permanente em relação a este fato, para que não comprometa a qualidade dos trabalhos de auditoria. Assim, identificar e gerir os atributos que podem levar os auditores a intenção de rotatividade é pertinente e primordial.

Uma possibilidade é por meio do capital psicológico, o qual segundo Luthans e Youssef (2004) produz um estado de acréscimo psicológico em que a pessoa apresenta uma elevada confiança para ser bem-sucedida em tarefas desafiadoras. Ademais, gera atribuições positivas acerca dos acontecimentos que vão se suceder no presente e futuro, manifesta perseverança em relação aos objetivos definidos, e mostra-se capaz de redirecionar os meios para atingir os fins. Também revela a capacidade de superar adversidades. Para Luthans, Luthans e Luthans (2004) o capital psicológico integra quatro dimensões da personalidade humana: autoeficácia, esperança, otimismo e resiliência, sendo estas dimensões mensuráveis, que podem ser desenvolvidas e, que possuem impacto sobre o desempenho (Chee-Leong \& Osman, 2010; Luthans et al., 2004; Yin-Fah et al., 2010).

A abordagem do capital psicológico e a intenção de rotatividade é pouco explorada em pesquisas nacionais e internacionais. Zhen e Mansor (2020) consideram que os estudos anteriores se preocuparam principalmente com as demandas externas dos empregados, relacionadas a salários, benefícios, condições de trabalho e pouco foco tem sido dado as necessidades internas com base no capital psicológico e intenção de rotatividade. Agapito, Polizzi Filho e Siqueira (2015) estudaram as relações entre as percepções de sucesso na carreira, o bem-estar no trabalho e a intenção de rotatividade em empresas públicas e privadas. Polizzi Filho e Claro (2019) buscaram testar um modelo teórico para intenção de rotatividade de professores, analisando sua relação com três dimensões de bem-estar no trabalho moderada pelo capital psicológico por meio das quatro dimensões das capacidades psicológicas: eficácia, otimismo, esperança e resiliência. Wubin e Zhao Liang (2010) investigaram a relação das dimensões de burnout e a intenção de rotatividade, inserindo a variável de Capital Psicológico como efeito moderador.

Sendo assim, a partir de pesquisas realizadas, não se localizou nenhum estudo que tenha estudado o Capital Psicológico no Trabalho relacionado com a Intenção de Rotatividade de auditores independentes. Frente ao exposto, destaca-se a seguinte questão que norteia o desenvolvimento desta pesquisa: Qual a influência do capital psicológico na intenção de rotatividade de auditores independentes? Com o intuito de responder a esta questão, o objetivo é verificar a influência do capital psicológico na intenção de rotatividade de auditores independentes. 
O estudo justifica-se pelo fato do capital psicológico se constituir em uma temática interessante e pouco abordada na área contábil, possibilitando a realização de diversas pesquisas, sobretudo com outras categorias profissionais. Zhen e Mansor (2020) enfatizam que a preocupação com o capital psicológico de empregados é importante não somente para evitar a intenção de rotatividade, retendo o indivíduo, mas também para garantir sua satisfação. Safavi e Bouzari (2020) consideram que estudos sobre profissionais que assumem responsabilidades e devem ser líderes (como é o caso de auditores) e sua relação com o capital psicológico ainda são negligenciados na literatura.

A importância de estudar a intenção de rotatividade de auditores independentes se justifica pois a maioria dos estudos com tais profissionais foca na importância ou não da rotatividade e seus reflexos na qualidade da auditoria, ou seja, diretamente relacionado a firma de auditoria. Porém, não buscam compreender por parte dos auditores, a intenção de rotatividade de auditores independentes, contexto recorrente nesta profissão (Muliawan, Green \& Robb, 2009) e por ser uma mão de obra especializada, a intenção de rotatividade se constitui num cenário desafiador às firmas de auditoria.

Broberg, Tagesson e Uman (2020) entendem que se o setor de auditoria quiser contrariar sua alta rotatividade de pessoal, tais firmas deveriam considerar sua estrutura de remuneração e sistema de recompensas. Complementam que a mudança no sistema de recompensa das firmas de auditoria seria, neste caso, às custas dos atuais sócios, o que pode ser uma ideia desanimadora para os mesmos. Porém, esta mudança pode ser necessária e oportuna para aumentar o bem-estar psicológico dos funcionários das firmas de auditoria e para evitar o aumento da rotatividade dos empregados das firmas de auditoria (Broberg et al., 2020). Masood, Siddiqui, Lodhi e Shahbaz (2020) afirmam que, por mais que a rotatividade continua sendo uma das principais preocupação nas pesquisas organizacionais, os autores entendem que a intenção de rotatividade de empregados precisa ser investigada de forma mais profunda, o que também justifica a realização do estudo.

O estudo contribui pois o capital psicológico pode ser utilizado em programas de desenvolvimento de recursos humanos, visto que possibilita mensurar a eficácia, esperança, otimismo e resiliência, de forma a implementar ações que possam compreender e mitigar a intenção de rotatividade nas firmas de auditoria (Avey, Reichard, Luthans \& Mhatre, 2011). O estudo avança justamente por analisar aspectos humanos e psicológicos na área contábil, especialmente no que se trata aos auditores, o que ainda divide opiniões relacionadas aos pontos positivos e negativos da rotatividade, sendo que a pesquisa também vai além por observar a intenção de rotatividade por parte dos próprios auditores independentes e não a rotatividade em si.

\section{REFERENCIAL TEÓRICO}

\subsection{Capital Psicológico no Trabalho e o Ambiente Organizacional da Auditoria}

A capacidade de os indivíduos adaptarem-se às mudanças que lhes são impostas no ambiente de trabalho é importante e necessária (Ferguson \& Reio, 2010; Luthans, Avolio, Avey \& Norman, 2007), até porque, diversas organizações atribuem maior relevância e valorizam mais os recursos humanos do que 
propriamente o capital financeiro (Avey, Patera \& West, 2006; Cunha, Rego, Lopes \& Ceitil, 2008; Luthans et al., 2007). Isso se torna uma vantagem competitiva frente às demais empresas (Mintzberg \& Lampel, 1999), que possuem a demanda de capital intelectual, sendo esta também uma realidade recorrente nas firmas de auditoria.

Uma vez que as atividades de auditoria procuram proporcionar segurança e confiabilidade nos relatórios financeiros da empresa auditada, supõe-se que as firmas de auditoria mantenham em seu quadro de funcionários auditores que reúnam capacitação adequada, habilidades e experiência para o exercício da sua função (Tato, 2008). Na expectativa da firma de auditoria oferecer um melhor trabalho aos seus clientes, é inerente que auditores sejam submetidos a fortes pressões, devido à relevância do resultado do seu trabalho para com os clientes da firma de auditoria (Oliveira \& Santos, 2007). Essas pressões podem gerar instabilidade nas capacidades psicológicas desses profissionais (Luthans et al., 2004), comprometendo a firma de auditoria em atingir seus objetivos.

O resultado do trabalho do auditor pode legitimar os relatórios financeiros ou revelar uma fraude. Isto será possível por meio de um trabalho eficiente e eficaz. No entanto, o inverso também é possível pelo risco de aplicar erroneamente um procedimento de auditoria ou ter interpretado erroneamente as evidências da auditoria, quando estiver submetido a fortes pressões. Naturalmente, os resultados negativos apresentam impacto mais significativo do que os positivos (Baumeister, Finkenaur \& Vohs, 2001).

A partir de toda a evolução, o estudo da psicologia tradicional foi aperfeiçoado e denominado de Psicologia Positiva, a qual, teve por intuito impulsionar pesquisas voltadas a resistência e força, vida saudável, ao invés de se preocupar apenas com as fraquezas e danos, que a psicologia tradicional se preocupava até então (Seligman \& Csikszentmihal, 2000; Siqueira, Martins \& Souza, 2014b). Seligman e Csikszentmihal (2000) ressaltam que as fraquezas e danos referem-se a: depressão, abuso de substâncias, doenças graves, e até mesmo a fome e a insatisfação do indivíduo com o trabalho. Com isso, a prevenção ganhou força para enfrentar esses problemas. Neste sentido as teorias motivacionais que explicam o porquê o indivíduo executa suas tarefas motivado, afastando a insatisfação com o trabalho.

Para Pajares e Olaz (2008), as crenças de autoeficácia permitem definir o que fazer, como fazer, por quanto tempo se fará e quanto esforço será necessário para realizar uma determinada tarefa. Essa estrutura lógica favorece as bases para a motivação do indivíduo, sendo as realizações pessoais e o bem-estar (Ferreira \& Azzi, 2010), o que contribui para que o indivíduo não se afaste do ambiente de trabalho. Conforme Bandura (1997), a autoeficácia percebida afeta os níveis de estresse e a saúde do indivíduo no trabalho. Assim, trabalhadores com alta eficácia percebida, optam em resolver problemas, adotando estratégias que melhoram suas tarefas. Já aqueles com baixa autoeficácia percebida, acreditam que pouco podem fazer para reverter a situação (Ferreira \& Azzi, 2010).

Diante da exposição sobre as teorias motivacionais e a partir deste movimento voltado ao Comportamento Organizacional Positivo (COP) tem-se a explicação da busca pela melhor qualidade de vida no trabalho pois, as capacidades e forças psicológicas orientadas de forma positiva, podem ser 
medidas, desenvolvidas e geridas para aumentar o desempenho no trabalho (Luthans, 2002). Para tanto, o capital psicológico no trabalho, abordagem central desse estudo, é resultante dos estudos do Comportamento Organizacional Positivo (COP).

De acordo com Hwang e Han (2018), indivíduos com capital psicológico mais elevado são mais propensos a ter confiança e alcançar resultados desejáveis por meio de seus esforços. Em relação a demanda de trabalho, a interação com os clientes pode ser fontes de fatores de estresse no trabalho, porém, o capital psicológico acaba ajudando a manter um clima positivo no ambiente de trabalho, com motivação elevada Hwang e Han (2018). Sendo assim, os autores ainda consideram que empregados com alto nível de capital psicológico podem ser menos propensos a experiências emocionais e possuem maior probabilidade de se identificar com o trabalho, sentirem-se satisfeitos.

Em relação ao capital psicológico, Luthans e Youssef (2004) apresentam quatro dimensões: autoeficácia, otimismo, esperança e resiliência, as quais refletem positivamente no exercício e desempenho das atividades do trabalhador. A Figura 1 apresenta um breve conceito de cada dimensão para melhor entendê-las e diferenciá-las.

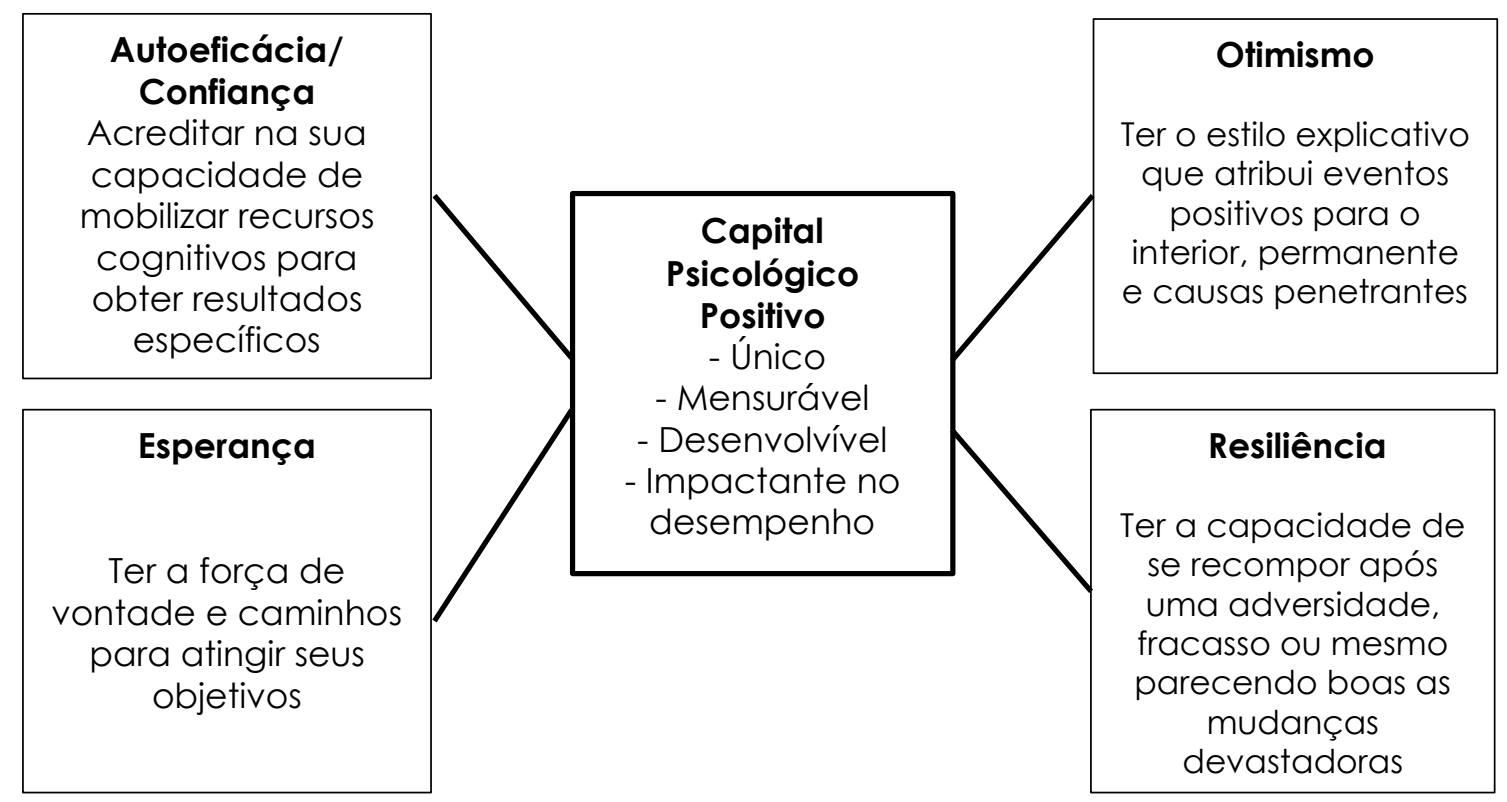

Figura 1 - Dimensões do capital psicológico positivo Fonte: (Luthans \& Youssef, 2004).

A primeira dimensão demonstrada na Figura 1 refere-se a autoeficácia que consiste na crença que o indivíduo possui a habilidade em motivar-se e realizar ações úteis, para que uma tarefa seja concretizada com êxito em um determinado ambiente (Luthans \& Youssef, 2004). A segunda dimensão do capital psicológico é a esperança que evidencia a convicção que o indivíduo possui de força de vontade e alternativas necessárias para atingir seus objetivos (Luthans \& Youssef, 2004). Para Snyder, Irving e Anderson (1991), a esperança retrata um estado emocional do indivíduo, consequência da convicção de dispor de recursos e os meios para ser bem-sucedido. 
O otimismo, terceira dimensão do capital psicológico, apresenta-se em indivíduos por acreditar que coisas boas irão acontecer (Carver \& Scheier, 2002), procurando minimizar os acontecimentos desfavoráveis. Para Seligman (2002), o otimismo é classificado em duas dimensões: permanência e penetrabilidade. A primeira retrata o modo com que o indivíduo encara os acontecimentos. Se for negativo, é concebido como temporário e caso contrário, é percebido como permanente. Já a penetrabilidade, retrata o impacto que os acontecimentos inferem na vida do indivíduo (Siqueira et al., 2014b). Por fim, tem-se a quarta dimensão, denominada resiliência, conceituada por Moraes e Rabinovich (1996) como uma combinação de fatores que ajudam o homem a enfrentar os problemas e situações adversas. É a capacidade que o indivíduo possui de recomposição diante de uma situação adversa ou de um fracasso, conseguindo ter uma reação positiva diante de cenários de mudanças significativos (Luthans \& Youssef, 2004).

Estudos envolvendo o capital psicológico tem demonstrado relações positivas com satisfação no trabalho, comprometimento organizacional, bemestar psicológico (Avey et al., 2011), comportamento desejáveis de cidadania e outras medidas de desempenho (auto avaliação, avaliação do supervisor e faturamento da empregadora) (Avey et al., 201 1; Siqueira et al., 2014b). Já a relação significativa e negativa, foi encontrada entre o capital psicológico e atitudes desejáveis (satisfação no trabalho, comprometimento organizacional, bem-estar psicológico), comportamento desejáveis de cidadania e outras medidas de desempenho (auto avaliação, avaliação do supervisor e faturamento da empregadora) (Avey et al., 2011; Siqueira et al., 2014b).

Por outro lado, relação significativa e negativa foi encontrada entre o capital psicológico e comportamentos indesejáveis e quadros psicológicos negativos como cinismo, intenções de rotatividade, estresse, ansiedade, além de atitudes contra produtivas dos trabalhadores (Avey et al., 2011; Siqueira et al., 2014b).

Kang e Busser (2018) testaram um modelo conceitual das inter-relações entre o clima de serviço, capital psicológico, envolvimento dos empregados e intenção de rotatividade e exploraram os efeitos mediadores. A amostra compreendeu funcionários da linha de frente (gestores) de hospitalidade. Os autores verificaram a partir dos resultados que o envolvimento do empregado medeia totalmente a relação entre capital psicológico, clima de serviço e intenção de rotatividade, destacando o efeito do engajamento dos empregados. Embora o impacto financeiro da rotatividade de empregados seja bem conhecido, a rotatividade não apenas aumenta o custo do quadro de funcionários, a alta intenção de rotatividade também faz com que a organização perca funcionários com uma alto grau de conhecimentos e habilidades, o que resulta em um impacto negativo na cultura organizacional e na moral dos empregados.

Dessa forma, fica a expectativa da aplicabilidade do capital psicológico no ambiente organizacional do auditor, pelo fato de que as dimensões do capital psicológico são mensuráveis, podem ser desenvolvidas e possuem impacto no desempenho das organizações (Luthans et al., 2004). 


\subsection{Intenção de Rotatividade e o Contexto da Auditoria}

Frequentemente o ambiente organizacional é afetado por fatores que interferem negativamente nas organizações. Embora a concorrência e a tecnologia possam ser consideradas como fatores que interferem nas empresas (Ferreira \& Siqueira, 2005), a insuficiência de recursos pode ser o foco de maior relevância a ser explorado, pois as empresas dependem de recursos para o recrutamento, seleção, capacitação e permanência do empregado, o que pode interferir nas estratégias competitivas (Mintzberg \& Lampel, 1999).

Diante disso, as políticas e práticas de gestão de pessoas devem estar alinhadas aos objetivos estratégicos das organizações (Oliveira \& Limongi-França, 2005), o que minimiza a perda de profissionais importantes às empresas. Para Gubman (1998), nas economias que evidenciam rápido crescimento, o acesso aos bons profissionais pode ser mais difícil, do que recursos financeiros e tecnológicos. Não é diferente nas firmas de auditoria, que se esforçam para encontrar e manter em seu quadro de pessoal, auditores com capacitação, habilidades e experiências para atuar nesse ambiente organizacional. Sendo assim, nas organizações que demandam maior capital intelectual, é fundamental identificar os fatores que levam a saída voluntária de seus empregados, para minimizar as perdas decorrentes da rotatividade de pessoal (Kazi \& Zadeh, 2011).

A rotatividade de pessoal ou turnover é o resultado da saída de colaboradores/empregados e da entrada de novos em substituição no trabalho (Chiavenato, 2010). O autor ainda aduz que, esse fluxo de entradas e saídas de pessoas em uma organização pode ser motivado por iniciativa da empresa ou do próprio empregado. A intenção de rotatividade pode estar relacionada com a insatisfação com o trabalho ou mesmo, insatisfação com o ambiente de trabalho. Por parte da empresa. Pode ocorrer para substituir por algum profissional mais adequado ao cargo ou insatisfação relacionado ao desempenho do empregado, por exemplo (Chiavenato, 2010).

O turnover nas firmas de auditoria, além de interromper uma sequência nos trabalhos, pode reduzir o conhecimento da metodologia aplicada por determinado auditor que, deixará a firma, ainda que os processos nas firmas de auditoria primem por padronização. Broberg et al. (2020) entendem que a atratividade das firmas de auditorias como empregadoras diminuiu nos últimos anos e a profissão de auditoria vem passando por alta rotatividade de empregados, o que ocorre normalmente quando há alta demanda por mão de obra. Além disso, outro indício de alta rotatividade é que os auditores independentes, segundo Yuen et al. (2013), podem se recusar a agirem de acordo com as instruções da alta administração, ao solicitarem o fornecimento de relatórios favoráveis aos clientes. Exceto se os profissionais não tiverem forte senso de profissionalismo (Yuen et al., 2013).

Para Morgan (2010) o turnover resulta em custos financeiros e não financeiros. Os financeiros referem-se ao desligamento, recrutamento, seleção, treinamentos e desenvolvimentos de pessoas (Siqueira, Gomide Jr., Oliveira \& Polizzi Filho, 2014a). Já os custos não financeiros, conforme Assis (2010), correspondem a perda de conhecimento, de capital intelectual, de inteligência e controle de processos. Cascio (1991) ressalta que os custos incorridos com a rotatividade de pessoal, normalmente não são controlados, devido a dificuldade de identificação dos fatores causadores. 
Logo, a intenção de rotatividade por auditores exige dos gestores das firmas de auditoria o desenvolvimento de novas estratégias para reter os talentos. Como se tratam de variáveis mensuráveis, Chang (1999) salienta que o turnover e a intenção de turnover devem ser medidos separadamente, pelo fato da intenção ser classificada como uma variável cognitiva e que posteriormente resultará no turnover.

Vandenberg e Nelson (1999) afirmam que, para compreender e controlar a intenção de rotatividade, é preciso identificar as causas que levam o empregado a manifestar a vontade de sair da organização. Nas firmas de auditoria, as causas da intenção de rotatividade, podem ser as fortes pressões incorridas nas atividades de campo, grandes jornadas de trabalho, capacidade de cumprimento de prazos e obrigações, lidar com cenários complexos, entre outras causas que são inerentes ao trabalho do auditor, afetando o seu desenvolvimento, desencadeando insatisfação e desmotivação em permanecer na firma de auditoria. Dessa forma, é preciso que as firmas de auditoria estejam atentas aos comportamentos dos empregados, para detectar quando este planeja sair da organização (Siqueira et al., 2014a) e estabelecer estratégias que visam a permanência do auditor.

Na perspectiva de encontrar outras variáveis explicativas para a intenção de rotatividade de empregados, Wubin e Zhao Liang (2010) realizaram uma análise entre a relação das dimensões de burnout e a intenção de rotatividade, e posteriormente inseriram a variável capital psicológico como moderadora. Os resultados revelaram que a realização pessoal pode causar mudanças em relação a intenção de rotatividade, quanto melhor estiverem, menores serão as chances de trocarem de empresa. Para tanto, destacam que o desenvolvimento do capital psicológico dos funcionários pode reduzir de forma eficaz a intenção de rotatividade.

Ainda que não verificado no cenário da auditoria, a intenção de rotatividade foi tema da pesquisa de Polizzi Filho e Claro (2019) que analisaram o impacto do bem-estar no trabalho sobre a intenção de rotatividade com a respectiva moderação do capital psicológico em professores universitários brasileiros. Os resultados demonstraram que, quanto maior é o nível de comprometimento do professor com a entidade escolar, menor será a intenção de turnover.

Broberg et al. (2020) verificaram a partir do seu estudo que a demografia, as condições de trabalho, satisfação no trabalho e na vida estão relacionadas com o bem-estar psicológico dos profissionais, incluindo auditores. Ademais, frisam que as divergências entre auditores e outros profissionais da área de negócios, como seus clientes, podem potencializar a intenção e a alta rotatividade no setor. Dessa forma, verificar a influência do Capital Psicológico no Trabalho, por meio das dimensões autoeficácia, esperança, otimismo e resiliência, na intenção de rotatividade dos auditores pode sinalizar para as firmas de auditoria, fatores que devem ser compreendidos e observados com mais atenção, com o intuito de reduzir a rotatividade na área de auditoria. 


\section{PROCEDIMENTOS METODOLÓGICOS}

Com o intuito de atender ao objetivo de verificar a influência do capital psicológico na intenção de rotatividade de auditores independentes, realizou-se uma pesquisa descritiva, de levantamento e com abordagem quantitativa. Os sujeitos da pesquisa foram auditores independentes com cadastro no Linkedinß. O convite foi enviado a 640 auditores independentes (brasileiros) que localizou-se no Linkedin ${ }^{\circledR}$ a partir do seguinte filtro para localização dos respondentes: "auditor(a) independente" e "auditores independentes". Na sequência, enviaram-se os convites, um a um, ou seja, a solicitação de contato com uma mensagem explicando a pesquisa e ressaltando a importância da participação dos auditores independentes. Após o convite aceito encaminhou-se o link dos questionários aos auditores. Dos 640 auditores independentes, 166 responderam devidamento o questionário.

O instrumento de coleta de dados se deu por meio de questionário de perguntas fechadas dividido em três blocos (Anexo). O primeiro bloco apresenta questões em relação ao perfil dos auditores com 4 questões, o segundo bloco relaciona-se com o Capital Psicológico contendo 25 questões de Siqueira et al. (2014b) é denominado Inventário de Capital Psicológico no Trabalho (ICPT-25), divididas em quatro dimensões: autoeficácia, esperança, otimismo e resiliência. Neste bloco utilizou-se a seguinte escala Likert: (1) Discordo totalmente; (2) Discordo; (3) Não concordo nem discordo; (4) Concordo; (5) Concordo totalmente. Por fim, o terceiro bloco relaciona-se com a intenção de rotatividade contendo 3 questões de Siqueira et al. (2014a) com a seguinte escala Likert: (1) Nunca; (2) Raramente; (3) às vezes; (4) Frequentemente; (5) Sempre, denominado demonimada de Escala de Intenção de Rotatividade (EIR). A Figura 2 apresenta as questões do Bloco 2 (capital psicológico) e Bloco 3 (intenção de rotatividade) segregadas por dimensão. 


\begin{tabular}{|c|c|c|}
\hline Dimensões & Código & Questões \\
\hline \multicolumn{3}{|r|}{ Capital Psicológico } \\
\hline \multirow{8}{*}{ Autoeficácia } & Auto_1 & Sou capaz de resolver problemas no meu trabalho. \\
\hline & Auto_5 & Sou capaz de cumprir as obrigações do meu trabalho. \\
\hline & Auto_9 & Sou capaz de dominar a tecnologia do meu trabalho. (B) \\
\hline & Auto_10 & Fico mais forte após enfrentar desafios no trabalho. \\
\hline & Auto_16 & $\begin{array}{l}\text { Sou capaz de dominar os procedimentos novos que surgem no } \\
\text { meu trabalho. } \AA\end{array}$ \\
\hline & Auto_20 & Sou capaz de realizar tarefas complexas no meu trabalho. (B) \\
\hline & Auto_21 & $\begin{array}{l}\text { Eu posso pensar em muitas maneiras de resolver um problema } \\
\text { no trabalho. }\end{array}$ \\
\hline & Auto_23 & Sou capaz de ser criativo no meu trabalho. \\
\hline \multirow{6}{*}{ Esperança } & Esp_2 & $\begin{array}{l}\text { Eu espero ter conhecimento suficiente para crescer no trabalho. } \\
\text { (B) }\end{array}$ \\
\hline & Esp_3 & $\begin{array}{l}\text { Eu posso encontrar muitas maneiras de realizar meus sonhos no } \\
\text { trabalho. } \mathbb{B}\end{array}$ \\
\hline & Esp_8 & $\begin{array}{l}\text { Eu espero ter energia suficiente para ser bem-sucedido no } \\
\text { trabalho. }\end{array}$ \\
\hline & Esp_13 & $\begin{array}{l}\text { Eu espero ter experiência suficiente para me sair bem no } \\
\text { trabalho. } \mathbb{B}\end{array}$ \\
\hline & Esp_14 & $\begin{array}{l}\text { Eu posso achar formas para mostrar ao meu chefe que faço bem } \\
\text { feito o meu trabalho. }\end{array}$ \\
\hline & Esp_19 & $\begin{array}{l}\text { Eu posso descobrir caminhos para atingir meus objetivos no } \\
\text { trabalho. }\end{array}$ \\
\hline \multirow{5}{*}{ Otimismo } & Otim_6 & Eu acredito que tudo dará certo comigo no meu trabalho. \\
\hline & Otim_11 & Eu acredito que dias melhores virão no meu trabalho. (B) \\
\hline & Otim_17 & $\begin{array}{l}\text { Eu acredito que coisas boas acontecerão comigo no meu } \\
\text { trabalho. } \AA\end{array}$ \\
\hline & Otim_18 & Eu espero ter planos para meu futuro no trabalho. \\
\hline & Otim_24 & Eu acredito que o amanhã será melhor no meu trabalho. ${ }^{\circledR}$ \\
\hline \multirow{6}{*}{ Resiliência } & Res_4 & Fico mais forte após enfrentar demissão no trabalho. \\
\hline & Res_7 & Fico mais forte após enfrentar mudanças no trabalho. \\
\hline & Res_12 & Fico mais forte após enfrentar perdas no trabalho. ${ }^{\circledR}$ \\
\hline & Res_15 & Fico mais forte após enfrentar dificuldades no trabalho. \\
\hline & Res_22 & Fico mais forte após enfrentar intrigas no trabalho. (B) \\
\hline & Res_25 & Fico mais forte após enfrentar inveja no trabalho. ${ }^{\circledR}$ \\
\hline \multicolumn{3}{|c|}{ Intenção de Rotatividade } \\
\hline Penso & Penso & Penso em sair da empresa onde trabalho. \\
\hline Planejo & Planejo & Planejo sair da empresa onde trabalho. \\
\hline $\begin{array}{l}\text { Tenho } \\
\text { Vontade }\end{array}$ & Vontade & apresa onde \\
\hline
\end{tabular}

Figura 2 - Escalas de medição do capital psicológico e da intenção de rotatividade Fonte: (Siqueira et al., 2014b; Siqueira et al., 2014a).

O questionário foi elaborado e enviado pelo Google Docs. A apuração dos resultados obtidos por meio do Inventário de Capital Psicológico no Trabalho (ICPT-25) produziu quatro escores médios, que foram obtidos somando-se os valores assinalados pelos auditores em cada um dos itens assinalados em cada dimensão e, em seguida dividiu-se esse valor pelo número de itens da dimensão. Os escores médios são altos quando ficarem entre 4 e 5; médios quando 
estiverem entre 3 e 3.9; e baixos quando ficarem entre 1 e 2.9 (Siqueira et al., 2014b).

A apuração dos resultados obtidos por meio da Escala de Intenção de Rotatividade (EIR) produz um escore médio, obtido pela soma dos valores assinalados pelos auditores nas três questões e dividido por três. Quanto aos valores obtidos pelos escores médios, classifica-se como alto um escore entre 4 e 5, médio um escore entre 3 e 3.9 e baixo quando se tem um escore entre 1 e 2.9. A interpretação dos resultados obtidos representa a frequência com que o auditor elabora planos mentais a respeito de sua saída da firma de auditoria (Siqueira et al., 2014a).

A análise dos dados ocorreu por meio de estatística descritiva e da técnica de regressão logística multinomial por meio do software SPSS $\AA_{\text {. A regressão }}$ logística multinomial é indicada por Fávero (2015) no momento em que se tem uma variável dependente, de natureza qualitativa, e que ofereça mais de duas possibilidades de resposta, ou seja, mais de duas categorias. Neste estudo a variável dependente foi a intenção de rotatividade e apresentava 3 alternativas (baixa, média e alta). Diante desse método é possível estimar probabilidades de ocorrência de cada uma das alternativas, sendo necessário definir uma como referência. No caso da Intenção de Rotatividade, a referência foi a baixa intenção de rotatividade (1). Além disso, na regressão logística adotam-se medidas de associação entre as variáveis, que correspondem ao coeficiente de determinação, também usado na regressão linear. É importante salientar que o coeficiente de Nagelkerke é coeficiente de determinação de uso mais comum e representa $\circ \mathrm{R}^{2}$.

Para as variáveis de perfil dos respondentes, foram criadas variáveis dicotômicas (0 e 1), sendo considerado como padrão, o conjunto que apresentou a maior frequência em cada grupo. Sendo assim, na idade a categoria padrão foi de 20 a 29 anos. Em relação ao cargo adotou-se como padrão o Sênior e no que tange o tempo de experiência adotou-se como padrão de 4.1 a 8 anos.

\section{ANÁLISE E DISCUSSÃO DOS RESULTADOS}

\subsection{Perfil dos Respondentes}

No que diz respeito ao sexo dos respondentes tem-se que, a maioria é do sexo masculino, o que corresponde a 69.3\%, ou seja, 115 auditores. As mulheres compreendem um total de 51, o que representa $30.7 \%$. A seguir, a partir da Tabela 1, apresenta-se uma análise do perfil dos respondentes considerando as variáveis sexo, idade, cargo e tempo de experiência em auditoria. 
Tabela 1

Perfil dos respondentes

\begin{tabular}{|c|c|c|c|c|c|c|}
\hline \multirow{3}{*}{ Perfil } & \multicolumn{2}{|c|}{ Homens } & \multicolumn{2}{|c|}{ Mulheres } & \multicolumn{2}{|c|}{ Total } \\
\hline & \multicolumn{6}{|c|}{ Idade } \\
\hline & $\begin{array}{c}\text { Frequência } \\
\text { absoluta }\end{array}$ & $\begin{array}{l}\text { Frequência } \\
\text { relativa (\%) }\end{array}$ & $\begin{array}{c}\text { Frequência } \\
\text { absoluta }\end{array}$ & $\begin{array}{l}\text { Frequência } \\
\text { relativa (\%) }\end{array}$ & $\begin{array}{c}\text { Frequência } \\
\text { absoluta }\end{array}$ & $\begin{array}{l}\text { Frequência } \\
\text { relativa (\%) }\end{array}$ \\
\hline De $20-29$ anos & 69 & $60 \%$ & 42 & $82 \%$ & 111 & $67 \%$ \\
\hline De $30-39$ anos & 33 & $29 \%$ & 8 & $16 \%$ & 41 & $25 \%$ \\
\hline De $40-49$ anos & 9 & $8 \%$ & 1 & $2 \%$ & 10 & $6 \%$ \\
\hline$>$ de 50 anos & 4 & $3 \%$ & 0 & $0 \%$ & 4 & $2 \%$ \\
\hline Total & 115 & $100 \%$ & 51 & $100 \%$ & 166 & $100 \%$ \\
\hline \multicolumn{7}{|c|}{ Cargo } \\
\hline Assistente & 18 & $16 \%$ & 18 & $35 \%$ & 36 & $22 \%$ \\
\hline Sênior & 67 & $58 \%$ & 29 & $57 \%$ & 96 & $58 \%$ \\
\hline $\begin{array}{l}\text { Gerente/ } \\
\text { Supervisor }\end{array}$ & 21 & $18 \%$ & 3 & $6 \%$ & 24 & $15 \%$ \\
\hline Sócio & 9 & $8 \%$ & 1 & $2 \%$ & 10 & $6 \%$ \\
\hline Total & 115 & $100 \%$ & 51 & $100 \%$ & 166 & $100 \%$ \\
\hline \multicolumn{7}{|c|}{ Tempo de Experiência } \\
\hline De 0 a 4 anos & 33 & $29 \%$ & 24 & $47 \%$ & 57 & $34 \%$ \\
\hline De 4,1 a 8 anos & 47 & $41 \%$ & 22 & $43 \%$ & 69 & $42 \%$ \\
\hline De 8,1 a 12 anos & 18 & $16 \%$ & 4 & $8 \%$ & 22 & $13 \%$ \\
\hline$>$ de 12 anos & 17 & $15 \%$ & 1 & $2 \%$ & 18 & $11 \%$ \\
\hline Total & 115 & $100 \%$ & 51 & $100 \%$ & 166 & $100 \%$ \\
\hline
\end{tabular}

Fonte: Dados da pesquisa.

A partir da Tabela 1 é possível notar que o perfil preponderante dos respondentes perpassa por homens, com faixa etária entre 20 a 29 anos, exercendo o cargo de auditor sênior e com tempo de atuação entre 4 a 8 anos. Verifica-se que a predominância de homens é recorrente e observada em diferentes pesquisas na área de auditoria (Edgley, Sharma e Anderson-Gough, 2016). As mulheres, por mais que sejam em menor número de respondentes, apresentam resultados semelhantes se comparadas as frequências relativas (\%) dos dois sexos. Contudo, a diferença é notável na experiência, na qual a maioria das mulheres atua de 0 a 4 anos, ou seja, apresentaram menor tempo de experiência de trabalho, se comparadas aos homens.

Destaca-se também que 130 auditores que responderam o questionário possuem cargo igual ou superior a auditor sênior e que 109 auditores possuem um tempo de atuação superior a 4 de anos atuação. Isto acaba por qualificar a amostra da pesquisa, uma vez que mediante o perfil apresentado, tem-se um grupo de auditores experientes com possibilidade de ter vivenciado diferentes situações possíveis no exercício da profissão. A partir da Tabela 2 são evidenciadas as frequências relativas (percentual) considerando idade e experiência versus cargo versus sexo. 


\section{Tabela 2}

Idade e experiência versus cargo e sexo dos respondentes

\begin{tabular}{l}
\hline \multirow{2}{*}{ Idade } \\
\cline { 2 - 10 }
\end{tabular}

Fonte: Dados da pesquisa.

Os resultados apresentados na Tabela 2 sinalizam uma possível tendência entre os cargos e sexos dos respondentes com a sua idade e tempo de experiência. Denota-se que tanto os homens como as mulheres são jovens (entre 20 a 29 anos) quando estão no cargo de assistente, o que já era esperado, visto que muitos se inserem no mercado de auditoria após o início do curso de graduação. A maioria dos respondentes neste cargo, apresentam até 4 anos de experiência, o que pode evidenciar uma média de tempo na auditoria para ser promovido de cargo. Neste quesito, observa-se que não há mulheres assistentes com mais de 4 anos de experiência, ao passo que 33\% dos homens estão distribuídos em diferentes faixas temporais de tempo de trabalho. Porém, tais observações não foram objeto de investigação, o que requer parcimônia na análise dos resultados e investigações futuras.

Observa-se ainda de que a categoria sênior é ocupada tanto por homens como mulheres de 20 a 29 aos e com um tempo de trabalho entre 4 a 8 anos. 0 cargo de gerente se concentra na faixa de 30 a 39 anos e exige experiência entre 4 a 12 anos. Neste quesito, há uma pequena inclinação das mulheres serem promovidas até os 39 anos e com tempo de trabalho superior a 4 anos e inferior a 12 anos. Ao passo que existe um pequeno número de auditores homens que são promovidos ao cargo de gerente com menos de 4 anos de experiência. Por outro lado, existem auditores homens na faixa de idade de 40 a 49 anos que exercem a função de gerente há mais de 12 anos. Percebe-se ainda uma concentração das sócias mulheres com a respectiva idade e tempo de experiência. Ao passo, que para os homens estes quesitos são mais pulverizados. 
Tabela 3

Intenção de rotatividade versus sexo versus cargo

\begin{tabular}{l|c|c|c|c|c|c|c|c|c|c|c|c}
\hline \multirow{2}{*}{ Cargo } & \multicolumn{9}{|c|}{ Homens } & \multicolumn{6}{c}{ Mulheres } \\
\cline { 2 - 15 } & $\mathbf{1}$ & $\mathbf{2}$ & $\mathbf{3}$ & $\mathbf{4}$ & $\mathbf{5}$ & Total & $\mathbf{1}$ & $\mathbf{2}$ & $\mathbf{3}$ & $\mathbf{4}$ & $\mathbf{5}$ & Total \\
\hline Assistente & $11 \%$ & $22 \%$ & $35 \%$ & $24 \%$ & $7 \%$ & $\mathbf{1 8}$ & $0 \%$ & $17 \%$ & $44 \%$ & $33 \%$ & $6 \%$ & $\mathbf{1 8}$ \\
\hline Sênior & $9 \%$ & $36 \%$ & $26 \%$ & $23 \%$ & $5 \%$ & $\mathbf{6 7}$ & $0 \%$ & $14 \%$ & $45 \%$ & $31 \%$ & $10 \%$ & $\mathbf{2 9}$ \\
\hline Gerente/Supervisor & $19 \%$ & $16 \%$ & $27 \%$ & $30 \%$ & $8 \%$ & $\mathbf{2 1}$ & $0 \%$ & $0 \%$ & $33 \%$ & $67 \%$ & $0 \%$ & $\mathbf{3}$ \\
\hline Sócio & $15 \%$ & $52 \%$ & $33 \%$ & $0 \%$ & $0 \%$ & $\mathbf{9}$ & $0 \%$ & $100 \%$ & $0 \%$ & $0 \%$ & $0 \%$ & $\mathbf{1}$ \\
\hline Total & \multicolumn{9}{|c|}{$\mathbf{1 1 5}$} & \multicolumn{3}{c}{$\mathbf{5 1}$} \\
\hline
\end{tabular}

Legenda: (1) Nunca; (2) Raramente; (3) Às vezes; (4) Frequentemente; (5) Sempre. EIR - Escala de Intenção de Rotatividade.

Fonte: Dados da pesquisa.

Observa-se na Tabela 3 que as mulheres nos cargos de assistente, sênior e gerente apresentam uma intenção de rotatividade maior que os homens, embora, as diferenças não sejam tão significativas. A maior concentração de respostas dos homens está nas escalas 2, 3 e 4 que indicam que os mesmos raramente, às vezes ou frequentemente tem intenção de rotatividade. No caso das mulheres a concentração também se deu nas escalas 3 e 4, o que indica que às vezes ou frequentemente há uma intenção de sair da firma de auditoria.

Um resultado que merece destaque é que o auditor no cargo de sócio possui baixa intenção de rotatividade, tanto para homens como para mulheres. Verifica-se que homens apresentam menor propensão de intenção de rotatividade do que as mulheres, exceto se comparar o cargo de Sócio, no qual as auditoras apresentam uma média geral ligeiramente mais baixa que dos homens. Tais resultados podem ser explicados devido ao fato de que quando o auditor(a) é sócio(a) da firma de auditoria, os mesmo(a)s já tenham galgado diferentes cargos na firma de auditoria, vivido diferentes experiências no âmbito de auditoria, e que tenham perfil e habilidades para permanecer na área.

Observa-se que os auditores com cargo de sócios foram os que apresentaram menor intenção de rotatividade e que os assistentes e gerentes/supervisor são os que possuem a maior intenção. Já no caso das mulheres os valores ficaram mais altos que dos homens, pois o gerente/supervisor é aquele indivíduo que tem a maior intenção de sair da firma de auditoria. Este resultado é coerente no que concerne as expectativas durante a carreira do auditor. Enquanto se está nos cargos de assistente e sênior, possivelmente é o período que o indivíduo questiona se a escolha pela profissão foi acertada, conhece melhor a rotina da profissão, verifica se seu perfil se adequa com as demandas da profissão. Quando o auditor está numa condição de sócio, estes pontos, de forma geral, foram superados e os mesmos alinham-se ao perfil do profissional.

A seguir, por meio da Tabela 4 são evidenciados os resultados que se referem ao capital psicológico de acordo com cada dimensão comparativamente com o cargo dos respondentes e o sexo. A escala correspondente nesse caso é de discordo totalmente (1) a concordo totalmente (5). Ressalta-se que foram somados os respondentes, já considerando o índice obtido entre baixo: 1; médio: 2 e; alto: 3 . 
Tabela 4

Capital psicológico versus sexo versus cargo

\begin{tabular}{|c|c|c|c|c|c|c|c|c|c|}
\hline \multirow{3}{*}{ Cargo } & \multicolumn{4}{|c|}{ Homens } & \multirow{2}{*}{\multicolumn{4}{|c|}{ Mulheres }} & \multirow{3}{*}{ Total } \\
\hline & \multicolumn{7}{|c|}{ Autoeficácia } & & \\
\hline & 1 & 2 & 3 & CPT & 1 & 2 & 3 & CPT & \\
\hline Assistente & 0 & 0 & 18 & 3.0 & 0 & 7 & 11 & 2.6 & 2.9 \\
\hline Sênior & 0 & 13 & 54 & 2.8 & 0 & 8 & 21 & 2.7 & 2.8 \\
\hline Gerente/Supervisor & 0 & 4 & 17 & 2.8 & 0 & 1 & 2 & 2.7 & 2.8 \\
\hline Sócio & 0 & 0 & 9 & 3.0 & 0 & 0 & 1 & 3.0 & 3.0 \\
\hline Total & 0 & 17 & 98 & 2.9 & 0 & 16 & 35 & 2.8 & 2.9 \\
\hline \multicolumn{10}{|c|}{ Esperança } \\
\hline Assistente & 0 & 1 & 17 & 2.9 & 0 & 7 & 11 & 2.6 & 2.8 \\
\hline Sênior & 0 & 15 & 52 & 2.8 & 0 & 8 & 21 & 2.7 & 2.8 \\
\hline Gerente/Supervisor & 0 & 6 & 15 & 2.7 & 0 & 2 & 1 & 2.3 & 2.6 \\
\hline Sócio & 0 & 1 & 8 & 2.9 & 0 & 0 & 1 & 3.0 & 2.9 \\
\hline Total & 0 & 23 & 92 & 2.8 & 0 & 17 & 34 & 2.7 & 2.8 \\
\hline \multicolumn{10}{|c|}{ Otimismo } \\
\hline Assistente & 2 & 3 & 13 & 2.6 & 3 & 7 & 8 & 2.3 & 2.5 \\
\hline Sênior & 5 & 28 & 34 & 2.4 & 2 & 11 & 16 & 2.5 & 2.4 \\
\hline Gerente/Supervisor & 2 & 11 & 8 & 2.3 & 0 & 2 & 1 & 2.3 & 2.3 \\
\hline Sócio & 0 & 2 & 7 & 2.8 & 0 & 0 & 1 & 3.0 & 2.8 \\
\hline Total & 9 & 44 & 62 & 2.5 & 5 & 20 & 26 & 2.5 & 2.5 \\
\hline \multicolumn{10}{|c|}{ Resiliência } \\
\hline Assistente & 2 & 15 & 1 & 1.9 & 7 & 10 & 1 & 1.7 & 1.8 \\
\hline Sênior & 8 & 49 & 10 & 2.0 & 14 & 14 & 1 & 1.6 & 1.8 \\
\hline Gerente/Supervisor & 4 & 13 & 4 & 2.0 & 1 & 2 & 0 & 1.7 & 1.85 \\
\hline Sócio & 2 & 6 & 1 & 1.9 & 0 & 1 & 0 & 2.0 & 1.95 \\
\hline Total & 16 & 83 & 16 & 2.0 & 22 & 27 & 2 & 1.7 & 1.85 \\
\hline
\end{tabular}

Legenda: (1) baixo - de 1 a 2.9; (2) médio - de 3 a 3.9; (3) alto - de 4 a 5.

CPT - Capital Psicológico no Trabalho.

Fonte: Dados da pesquisa.

A Tabela 4 demonstra que a autoeficácia é a dimensão do Capital Psicológico com maior escore médio por parte dos respondentes, tanto homens quanto mulheres. Observa-se que tanto para os auditores como para as auditoras o escore geral foi de 2.9, considerado alto e demonstrando que os respondentes têm fortalecidas as crenças quanto a autoeficácia. Destaca-se também que os escores apresentados nesta dimensão foram os maiores em relação as demais dimensões, quando relacionado ao cargo.

Quando se analisa a dimensão esperança, verifica-se que homens no geral, possuem maior esperança que as mulheres. No caso das mulheres, somente a que ocupa cargo de sócia apresenta características de esperança maior que os homens que atuam neste mesmo cargo. Ao analisar a média das respostas dos homens e das mulheres conjuntamente, nota-se que o mesmo vai de 2.6 a 2.9, o que indica baixa capacidade psicológica em relação a esperança, por mais que a maioria dos respondentes responderam que concordam ou concordam totalmente com as questões relacionadas à esta dimensão. Destaca-se que a dimensão esperança trata da convicção de que o indivíduo possui de força de vontade e alternativas necessárias para atingir seus objetivos (Luthans \& Youssef, 2004).

Ao verificar o otimismo dos auditores independentes, tanto homens quanto mulheres, percebe-se que a concentração média das respostas ficou entre 4 e 5 
na escala de medição, o que indica que os respondentes apresentam alta capacidade psicológica relativa à essa dimensão. Contudo, homens assistentes apresentam no geral, um pouco mais de otimismo do que as mulheres. $O$ contrário é notável para o cargo de sócio assumido por mulheres, visto que apresentou um médio nível de capacidade psicológica, ficando acima da média geral dos homens. Já o cargo gerente/supervisor apresentou o mesmo resultado geral para ambos os sexos. Entretanto, somando a média das respostas dos homens e das mulheres sobre otimismo, nota-se que a capacidade psicológica no trabalho em relação à essa dimensão é baixa.

Relacionado a resiliência, percebe-se que a maioria dos homens, ao calcular a média, indiciou que nem concordo e nem discorda ou concorda com as questões relativas a resiliência no trabalho, ou seja, os mesmos responderam que não conseguem superar as adversidades no trabalho, ou apresentam dificuldades para se adaptar à novas situações. Ao analisar a média da pontuação desse sexo, nota-se que todos os cargos apresentam respostas parecidas, tanto é que a média ficou entre 1.9 e 2.0. No geral, a média ficou a mais baixa de todas as dimensões, para todos os cargos, contatando também a baixa capacidade psicológica de ambos os sexos.

Diante do exposto entende-se que no geral os auditores, tanto homens quanto mulheres, apresentam uma capacidade psicológica média de autoeficácia, ou seja, de acreditar na sua capacidade de mobilizar recursos cognitivos para obter resultados específicos; de otimismo, que se resume a ter o estilo explicativo que atribui eventos positivos no seu cotidiano; de resiliência, na qual os indivíduos possuem a capacidade de se recompor após uma adversidade, fracasso e; de esperança, no qual possuem força de vontade e caminhos para atingir seus objetivos.

\subsection{Influência do capital psicológico na intenção de rotatividade}

A partir da Tabela 5 apresentam-se os coeficientes estimados do modelo multinominal, obtido a partir da regressão logística multinomial. Como conjunto padrão da intenção de rotatividade optou-se pela baixa intenção (1). 
Tabela 5

Coeficientes estimados do modelo multinominal

\begin{tabular}{|c|c|c|c|c|c|c|}
\hline $\begin{array}{l}\text { Intenção de } \\
\text { Rotatividade }\end{array}$ & \multicolumn{3}{|c|}{$\begin{array}{c}\text { Interceptação } 2 \text { - Média Intenção } \\
\text { de Rotatividade }\end{array}$} & \multicolumn{3}{|c|}{$\begin{array}{c}\text { Interceptação } 3 \text { - Alta Intenção de } \\
\text { Rotatividade }\end{array}$} \\
\hline Modelo & B & $\begin{array}{c}\text { Erro } \\
\text { Padrão }\end{array}$ & Sig. & B & $\begin{array}{c}\text { Erro } \\
\text { Padrão }\end{array}$ & Sig. \\
\hline Constante & -1.811 & 2.337 & 0.438 & -30.332 & 1961.540 & 0.988 \\
\hline Sexo & -0.447 & 0.479 & 0.350 & -0.895 & 0.583 & 0.125 \\
\hline Idade 30 à 39 & 1.155 & 0.715 & 0.106 & -0.160 & 0.766 & 0.835 \\
\hline dade 40 à 49 & 1.242 & 1.368 & 0.364 & 1.253 & 1.723 & 0.467 \\
\hline Idade $>50$ & 1.683 & 1.834 & 0.359 & 15.417 & 0.000 & \\
\hline Experiência 0 a 4 & 0.521 & 0.540 & 0.334 & 0.129 & 0.693 & 0.853 \\
\hline Experiência 8 à 12 & -0.560 & 0.819 & 0.494 & 0.024 & 0.933 & 0.979 \\
\hline Experiência > 12 & 2.124 & 1.569 & 0.176 & 0.495 & 1.358 & 0.715 \\
\hline Cargo_Assistente & -0.911 & 0.598 & 0.128 & -0.592 & 0.781 & 0.448 \\
\hline Cargo_Gerente & -0.979 & 0.722 & 0.175 & -0.963 & 0.781 & 0.218 \\
\hline Cargo_Sócio & -2.851 & 1.445 & $0.048^{* *}$ & 14.364 & 1961.539 & 0.994 \\
\hline Esperança (médio) & 0.120 & 0.630 & 0.849 & 0.119 & 0.678 & 0.861 \\
\hline Resiliência (baixo) & 0.764 & 0.832 & 0.359 & -0.890 & 0.940 & 0.344 \\
\hline Resiliência (médio) & -0.211 & 0.697 & 0.762 & -1.199 & 0.727 & $0.099 *$ \\
\hline Otimismo (baixo) & 16.708 & 1925.661 & 0.993 & 18.919 & 1925.661 & 0.992 \\
\hline Otimismo (médio) & 1.221 & 0.479 & $0.011^{* *}$ & 1.902 & 0.572 & $0.001^{* * *}$ \\
\hline $\begin{array}{l}\text { Autoeficácia } \\
\text { (médio) }\end{array}$ & 0.472 & 0.649 & 0.468 & 0.579 & 0.725 & 0.425 \\
\hline Qui-quadrado (df) & \multicolumn{6}{|c|}{$70.004(32)$} \\
\hline Sig. & \multicolumn{6}{|c|}{0.000} \\
\hline Nagelkerke & \multicolumn{6}{|c|}{0.390} \\
\hline $\begin{array}{l}\text { ***Significante ao } \\
\text { ** Significante ao } \\
\text { * Significante ao n }\end{array}$ & $\begin{array}{l}\text { de } 1 \% . \\
\text { de } 5 \% . \\
\text { de } 10 \% .\end{array}$ & & & & & \\
\hline
\end{tabular}

Por meio da Tabela 5 observa-se que o modelo foi significativo ao nível de $5 \%$ com capacidade de explicação de $39.0 \%$ das variações registradas na variável dependente, o que é considerado um poder explicativo fraco, de acordo com Fávero (2015). Verifica-se que apenas as variáveis cargo sócio e médio otimismo apresentaram relação com a média intenção de rotatividade, sendo essa significativa ao nível de $5 \%$. O sócio esteve relacionado negativamente e o otimismo médio demonstrou relação positiva. Sendo assim, a partir dos resultados nota-se que os auditores sócios apresentam menor intenção média de rotatividade. Este resultado de certa forma mostrou-se esperado pelo fato de que o auditor até chegar a sociedade da firma de auditoria, passou por diferentes experiências e alcançou o estágio na qual a permanência na firma de auditoria é resultado do foco e do seu trabalho. Logo, a existência da intenção de rotatividade neste estágio da vida profissional deve figurar com menor possibilidade. Este achado converge com os resultados da intenção de rotatividade demonstrados na Tabela 4 em que a maioria dos auditores sócios nunca ou raramente apresentam uma intenção de rotatividade.

Ainda na Tabela 5 observa-se que auditores que apresentam otimismo médio possuem uma intenção média de sair da firma de auditoria. Este resultado demonstra que os auditores com médio otimismo, ainda não acreditam suficientemente que coisas boas podem acontecer no que diz respeito à sua 
atividade na firma de auditoria, o que é sustentado por Carver e Scheier (2002), demonstrando que se tenha a intenção de trocar de firma. Este médio otimismo dos auditores pode estar relacionado ao fato de como os mesmos encaram os acontecimentos cotidianos e qual o impacto desses acontecimentos na sua vida (Siqueira et al., 2014b).

Quanto a alta intenção de rotatividade, tem-se que auditores com resiliência média e médio otimismo apresentaram relação negativa e positiva respectivamente, sendo que a resiliência (média) foi significante ao nível de $10 \%$ e o otimismo (médio) de 1\%. Diante disso, entende-se que pessoas que apresentam resiliência média, possuem menor propensão a intenção alta de rotatividade, ou seja, não têm propensão alta de trocarem de firma de auditoria. Esse perfil de auditor, com um poder de médio resiliência, apresenta condições de reagir bem diante de adversidades vivenciadas no trabalho, pois sentem-se mais fortes diante de mudanças, perdas, dificuldades e/ou intrigas no trabalho. Este resultado converge com Avey et al. (2011) que encontraram uma relação significativa e negativa, entre o capital psicológico e a intenção de rotatividade, contudo, nesta pesquisa a relação apresentou-se negativa somente no caso da média resiliência com a alta intenção de rotatividade.

De forma geral, pelos resultados apresentados, destaca-se que a partir do momento em que o auditor confiar na realização de suas tarefas e estiver realmente motivado e com alta capacidade de superar as adversidades, ou seja, apresentar-se resiliente, haverá uma menor chance deste indivíduo ter a intenção de sair da firma na qual atua, o que também reduz custos para a firma de auditoria. Para Avey et al. (2011), programas de desenvolvimento de recursos humanos diminuem a rotatividade dos auditores nas organizações, sendo uma solução possível e importante para as firmas. Nesse mesmo sentido, Oliveira e Limongi-França (2005) destacam que políticas e práticas de gestão de pessoas devem estar alinhadas aos objetivos estratégicos das firmas, o que reduzirá a perda de profissionais importantes para as empresas.

De forma complementar, com intuito de proporcionar maior robustez nos achados, realizou-se na seção seguinte a regressão logística multinomial sem considerar o perfil dos respondentes.

\subsection{Influência do capital psicológico na intenção de rotatividade sem as variáveis do perfil do respondente}

A partir da Tabela 6 apresenta-se o teste de robustez, no qual foram retiradas as variáveis de perfil do modelo. Os resultados são apresentados na Tabela 6. 
Tabela 6

Teste de robustez dos coeficientes estimados do modelo multinominal

\begin{tabular}{|c|c|c|c|c|c|c|}
\hline \multirow{2}{*}{$\begin{array}{c}\text { Intenção de } \\
\text { Rotatividade } \\
\text { Modelo }\end{array}$} & \multicolumn{3}{|c|}{$\begin{array}{c}\text { Interceptação } 2 \text { - Média Intenção } \\
\text { de Rotatividade }\end{array}$} & \multicolumn{3}{|c|}{$\begin{array}{c}\text { Interceptação } 3 \text { - Alta Intenção de } \\
\text { Rotatividade }\end{array}$} \\
\hline & B & $\begin{array}{c}\text { Erro } \\
\text { Padrão }\end{array}$ & Sig. & B & $\begin{array}{c}\text { Erro } \\
\text { Padrão }\end{array}$ & Sig. \\
\hline Constante & -0.938 & 0.608 & 0.123 & -0.901 & 0.587 & 0.125 \\
\hline Esperança (médio) & 0.131 & 0.571 & 0.819 & 0.359 & 0.623 & 0.564 \\
\hline Resiliência (baixo) & 0.881 & 0.765 & 0.250 & -0.621 & 0.836 & 0.458 \\
\hline Resiliência (médio) & -0.019 & 0.658 & 0.977 & -1.199 & 0.684 & $0.080^{*}$ \\
\hline Otimismo (baixo) & 19.859 & 0.841 & $0.000 * * *$ & 21.808 & 0.000 & \\
\hline Otimismo (médio) & 0.957 & 0.433 & $0.027^{* *}$ & 1.670 & 0.538 & $0.002^{* *}$ \\
\hline $\begin{array}{l}\text { Autoeficácia } \\
\text { (médio) }\end{array}$ & 0.499 & 0.598 & 0.404 & 0.601 & 0.666 & 0.367 \\
\hline Qui-quadrado (df) & \multicolumn{6}{|c|}{$48.943(12)$} \\
\hline Sig. & \multicolumn{6}{|c|}{0.000} \\
\hline Nagelkerke & \multicolumn{6}{|c|}{0.289} \\
\hline
\end{tabular}

Fonte: Dados da pesquisa.

A partir das evidências expostas na Tabela 6 é possível notar que os resultados apresentam-se semelhantes ao modelo anterior, apresentado na Tabela 6. Para tanto, nota-se que novamente é possível confirmar uma relação entre as variáveis, visto que o modelo se apresentou significativo, contudo, o poder explicativo ficou menor que o anterior, sendo este de $28.9 \%$.

É possível perceber que além das variáveis que já tinham apresentado relação com a intenção de rotatividade, ou seja, médio otimismo com a média intenção e, média resiliência e médio otimismo com alta intenção de rotatividade, a variável baixo otimismo também se apresentou significativa neste modelo.

Dessa forma, entende-se que quanto menor a resiliência média, ou seja, menor for a capacidade de superar as adversidades, maior será a alta intenção de rotatividade. Para tanto, é importante que as firmas de auditoria observem tais informações, com vistas a identificar e compreender as variáveis da capacidade psicológica dos auditores para que seja reduzida essa intenção.

\section{CONCLUSÃO}

Este estudo teve por objetivo verificar a influência do capital psicológico na intenção de rotatividade de auditores independentes. Realizou-se pesquisa descritiva, de levantamento e quantitativa. A amostra foi composta por 166 auditores independentes. Para a análise dos dados utilizou-se análise descritiva de frequências e regressão logística multinomial.

O perfil dos participantes da pesquisa predominantemente são homens, com faixa etária entre 20 e 29 anos, ocupando o cargo de auditor sênior e com tempo de atuação entre 4 a 8 anos. As mulheres nos cargos de assistente, sênior e gerente apresentam uma intenção de rotatividade maior que os homens, ainda 
que não tão significativos. A intenção de rotatividade entre os homens apresentase mais distribuídos ao longo da carreira, exceto no cargo de sócio em que tanto para homens, como para as mulheres, a intenção de rotatividade é mais baixa comparativamente aos demais cargos.

Constatou-se com o estudo que das quatro dimensões do capital psicológico os auditores apresentam o maior escore na dimensão autoeficácia, ou seja, os auditores participantes da pesquisa acreditam na sua capacidade de mobilizar recursos cognitivos para obter os resultados desejados. Na dimensão esperança, em que se verifica a força de vontade e caminhos nos quais os indivíduos possuem para atingir seus objetivos, constatou-se que esta dimensão para os homens é maior do que para as mulheres, ainda que a dimensão como um todo, apresentou um escore baixo nos auditores investigados. Resultado semelhante foi encontrado quando se analisa a dimensão otimismo, em que se encontraram escores entre 2.3 a 2.8 tanto para homens como para as mulheres. A última dimensão (resiliência - em que se observa a capacidade de se recompor após adversidade ou fracassos) apresentou o menor escore médio obtido dentre as demais dimensões do capital psicológico.

Ao realizar a verificação da influência das quatro dimensões do capital psicológico na intenção de rotatividade, obteve-se uma significância de $5 \%$ capaz de explicar cerca de $39.0 \%$ da intenção de rotatividade. Neste caso, diferente do teste complementar que não foram incluídas as variáveis de perfil, os auditores sócios apresentaram menor intenção média de rotatividade. Este teste complementar ligeiramente obteve-se um poder de explicação menor, cerca de $28.9 \%$.

Diante dos resultados encontrados, pode-se concluir que há relação do capital psicológico de auditores independentes com a intenção de rotatividade no trabalho a partir das dimensões otimismo e resiliência. Para a dimensão otimismo médio há influência na média intenção de rotatividade dos auditores e também para a alta intenção de rotatividade. Já para a dimensão de resiliência média verificou-se uma influência com a alta intenção de rotatividade dos auditores.

Quando se verificou a influência do capital psicológico na intenção de rotatividade, sem considerar as variáveis de perfil do auditor, o otimismo médio se confirmou com a média intenção de rotatividade, acrescendo neste caso uma influência também do otimismo baixo. O Otimismo baixo também demonstrou influência na alta rotatividade dos auditores, assim como a resiliência média.

Conclui-se dessa forma que, auditores que apresentam baixo e médio otimismo, capacidade de ter uma perspectiva positiva diante do trabalho, proporciona maiores planos dos auditores quererem sair da firma de auditoria. Da mesma forma, auditores com baixa capacidade de resiliência, ou seja, de se recompor diante de fracassos e adversidades no trabalho, influenciam na alta intenção de sair da firma de auditoria.

O estudo contribui teoricamente por analisar a relação de duas temáticas até então não relacionadas na área contábil, especialmente na auditoria. Contribui também por trazer aspectos humanos e psicológicos para a área contábil, trabalhando assim a interdisciplinaridade. De forma empírica, contribui por identificar os aspectos relacionados ao capital psicológico que influenciam a intenção de rotatividade de auditores independentes, o que podem fazem com 
que as firmas de auditoria consigam mitigar ou reduzir essa intenção, colocando esforços em pontos que façam com que os auditores sintam maior satisfação com o trabalho, e tenham mais autoeficácia, otimismo, esperança e resiliência.

Portanto, a partir dos achados desta pesquisa as firmas de auditoria podem dar mais atenção as dimensões do capital psicológico, principalmente àquelas que tiveram relação com a intenção de rotatividade, isto é, a otimismo e resiliência, criando estratégias para que os auditores se sintam motivados, valorizados, lhes deem melhores oportunidades para que possam permanecer na firma de auditoria que atuam, diminuindo gastos em relação ao recrutamento, seleção e aumentando a possibilidade de se fortalecer cada vez no mercado competitivo, com profissionais experientes, qualificados.

O estudo limita-se por considerar auditores independentes brasileiros e devido a fonte de coleta dos dados utilizada. Outra limitação pode decorrer da forma de análise dos dados adotada, porém, utilizou-se aquela que foi considerada a mais adequada para atingir o objetivo e responder ao problema de pesquisa. Como sugestão para pesquisas futuras pode-se buscar um esforço para aumentar a amostra, além de analisar os reflexos do otimismo e da esperança na autoeficácia dos auditores, mediados pela capacidade de resiliência. Outros métodos de análise de dados podem ser interessantes, bem como, aplicar o questionário à outros profissionais da área contábil ou mesmo, de outras áreas que apresentem lacunas com as identificadas para a realização do presente estudo.

\section{REFERÊNCIAS}

Agapito, P. R., Polizzi Filho, A. \& Siqueira, M. M. M. (2015). "Bem-Estar no Trabalho e Percepção de Sucesso na Carreira como Antecedentes de Intenção de Rotatividade", Revista de Administração Mackenzie, 16(6), 71-93. DOI: https://doi.org/10.1590/1678-69712015/administracao.v16n6p71-93.

Assis, M. T. (2010). Indicadores de gestão de recursos humanos. Qualitymark, Rio de Janeiro.

Avey, J. B., Patera, J. L. \& West, B. J. (2006). "The implications of positive psychological capital on employee absenteeism", Journal of Leadership \& Organizational Studies, 13(2), 42-60. DOI: 10.1177/10717919070130020401.

Avey, J. B., Reichard R. J., Luthans F. \& Mhatre K. H. (2011). "Meta-analysis of the impact of positive psychological capital on employee attitudes, behaviors, and performance", Human Resource Development Quarterlv, 22(2), 127-152. DOI: 10.1002/hrdq.20070.

Bandura, A. (1997). Self-efficacy: the exercise of control. New York.

Baumeister, R. F., Bratslavsky E., Finkenaur C. \& Vohs K. D. (2001). "Bad is stronger than good", Review of General Psychology, 5(1), 323-370. DOl: https://doi.org/10.1037/1089-2680.5.4.323. 
Beuren, I. M., Ribeiro, F., \& Silva, O. L. (2019). "Percepção de justiça organizacional e intenção de turnover em empresas de auditoria". Revista de Ciências da Administração, 21(53), 93-111. DOI: https://doi.org/10.5007/21758077.2019V2 1 n53p93.

Broberg, P., Tagesson, T., \& Uman, T. (2020). "Antecedentes do bem-estar psicológico entre funcionários de firmas de auditoria suecas". Jornal Internacional de Pesquisa Ambiental e Saúde Pública, 17(10), 33-46. DOI: https://doi.org/10.1590/1678-6971/eRAMD200105.

Campos, C. V. A. \& Malik, A. M. (2008). "Satisfação no trabalho e rotatividade dos médicos do Programa de Saúde da Família", Revista de Administração Pública, 42(2), 347-368. DOl: https://doi.org/10.1590/S003476122008000200007.

Carver, C. S. \& Scfieier, M. F. (2002). "Optimism". In: Lopez, S. J., \& Snyder, C. R. (Org.). Handbook of positive psychology. Oxford University, New York.

Cascio, W. (1991). Costing Human Resources: The Financial Impact of Behavior in Organizations, $3 a$ ed., Ed. Boston: PWS-KENT Publishing Company.

Chang, E. (1999). "Career Commitment as a Complex Moderator of Organizational Commitment and Turnover Intention", Human Relations, 52 (10), 1257-1278. DOl: https://doi.org/10.1177/001872679905201002.

Chiavenato, I. (2010). Gestão de Pessoas: o novo papel dos recursos humanos nas organizações. Rio de Janeiro: Elsevier.

Cunha, M. P., Rego, A., Lopes, M. P. \& Ceitil, M. (2008). Organizações positivas: manual de trabalho e formação para desenvolver as forças dos indivíduos e das organizações. Sílabo, Lisboa.

Edgley, C., Sharma, N. \& Anderson-Gough, F. (2016). "Diversity and professionalism in the Big Four Firms: Expectation, celebration and weapon in the battle for talent", Critical Perspectives on Accounting, 35, 13-34. DOl: https://doi.org/10.1016/j.cpa.2015.05.005.

Fávero, L. P. (2015). Análise de dados: modelos de regressão com Excel ${ }^{\circledR}$, Stata ${ }^{\circledR}$ e SPSS ${ }^{\circledR}$. la ed. Elsevier.

Ferguson, K. L. \& Reio Jr., T. G. (2010). "Human resource management systems and firm performance", Journal of Management Development, 29(5), 471-494. DOI: https://doi.org/10.1108/02621711011039231.

Ferreira, L. C. M. \& Azzi R. G. (2010). "Docência, burnout e considerações da teoria da autoeficácia", Psicologia Ensino \& Formação, 1 (2), 23-34.

Gubman, E. (1998). The talent solution: aligning strategy and people to achieve extraordinary results. McGraw-Hill, New York.

Hammes, C. C. F., Santos, A. J., \& Melim, J. M. (2016). "Os impactos do turnover para as organizações". Revista Espacios, 37(03), 1-24. 
Kazi, G. M. \& Zadeh, Z. F. (2011). "The contribution of individual variables: job satisfaction and job turnover", IJCRB - Interdisciplinary Journal of Contemporary Research in Business, 3(5), 985-992.

Luthans, F. (2002). "The need for and meaning of positive organizational behavior", Journal of Organizational Behavior, 23(6), 695-706. DOI: https://doi.org/10.1002/job. 165.

Luthans, F., Avolio, B., Avey, J. \& Norman, S. (2007). "Positive psychological capital: measurement and relationship with performance and satisfaction", Personnel Psychology, (60), 541-72. DOl: https://doi.org/10.1111/j.1744-6570.2007.00083.x.

Luthans, F., Luthans, K. W. \& Luthans, B. C. (2004). "Positive psychological capital: beyond human and social capital", Business Horizons, 41(1), 45-50. DOI: https://doi.org/10.1016/j.bushor.2003.11.007.

Luthans, F. \& Youssef, C. M. (2004). "Human, social and now positive psychological capital management: investing in people for competitive advantage", Organizational Dynamics, 33 (2), 143-160. DOl: https://doi.org/10.1016/j.orgdyn.2004.01.003.

Martinez, A. L. (2010). "Quando o conselho de administração e a auditoria evitam - gerenciamento de resultados? Evidências empíricas para empresas brasileiras". Revista de Informação Contábil, 4(1), 76-93. DOI: https://doi.org/10.34629/ric.v4i1 .76-93.

Masood, S., Siddiqui, G. K., Lodhi, H., \& Shahbaz, S. (2020). "Effect of Leadership Styles on Organizational Citizenship Behavior and Employee Turnover Intention". Journal of Accounting and Finance in Emerging Economies, 6(2), 487-495. DOI:10.26710/jafee.v6i2.1200.

Mintzberg, H. \& Lampel, J. (1999). "Reflecting on the strategy process", MIT Sloan Management Review, 40(3), 21-30.

Mobley, W. H. (1977). "Intermediate linkages in the relationship between job satisfaction and employee turnover", Journal of Applied Psychology, 62 (2), 237-240. DOI: https://doi.org/10.1037/0021-9010.62.2.237.

Moraes, M. C. L. \& Rabinovich, E. P. (1996). "Resiliência uma discussão introdutória". Journal of Human Growth and Development, 6(1-2), 10-13. DOI: https://doi.org/10.7322/jhgd.38369.

Morgan, G. (2010). Imagens da organização. 2a ed. Atlas, São Paulo.

Muliawan, A. D., Green, P. F. \& Robb, D. A. (2009). "The turnover intentions of information systems auditors", International Journal of Accounting Information Systems, 10(3), 117-136. DOI: https://doi.org/10.1016/j.accinf.2009.03.001.

Oliveira, A. Q. \& Santos, S. N. M. B. F. (2007). "Rodízio de firmas de auditoria: a experiência brasileira e as conclusões do mercado", Revista Contabilidade \& Finanças, 18(45), 91-100. DOI: https://doi.org/10.1590/S151970772007000400009. 
Oliveira, P. M. \& Limongi-França, A. C. (2005). "Avaliação da gestão de programas de qualidade de vida no trabalho", RAE-eletrônica, 4(1).

Pajares, F. \& Olaz, F. (2008). "Teoria social cognitiva e auto-eficácia: uma visão geral", Teoria social cognitiva: Conceitos básicos, 97-114.

Polizzi Filho, A. \& Claro, J. A. C. S. (2019). "O impacto de bem-estar no trabalho e de capital psicológico sobre intenção de rotatividade: um estudo com professores", RAM, Rev. Adm. Mackenzie, 20(2), 1-27. DOI: https://doi.org/10.1590/1678-6971/eRAMG190064.

Ribeiro, A. C. (2019). O Impacto da Auditoria Interna na Gestão de uma Organização. 94f. 2019. Dissertação (Mestrado em Auditoria), Instituto Superior de Contabilidade e Administração do Porto, Portugal, 2019.

Safavi, H. P., \& Bouzari, M. (2020). "How can leaders enhance employees' psychological capital? Mediation effect of person-group and personsupervisor fit". Tourism Management Perspectives, 33, 1-9. DOI: https://doi.org/10.1016/j.tmp.2019.100626.

Seligman, M. E. E \& Csikszentmihalyi, M. (2000)." Positive psychology: an introduction", American Psychologist, 55(1), 5-14. DOl:10.1037/0003066X.55.1.5.

Seligman, M. E. P. (2002). Felicidade autêntica. Editora Objetiva.

Siqueira, M. M. M., Gomide Jr., S., De Oliveira, Á. F. \& Polizzi Filho, A. (2014a). "Intenção de Rotatividade". In: Siqueira, M. M. M. (Org.). Novas Medidas do Comportamento Organizacional: Ferramentas de diagnóstico e de Gestão. Artmed, Porto Alegre.

Siqueira, M. M. M., Martins, M. C. F. \& Souza, W. da S. (2014b). "Capital Psicológico no trabalho". In: Siqueira, M. M. M. (Org.). Novas Medidas do Comportamento Organizacional: Ferramentas de diagnóstico e de Gestão. Artmed, Porto Alegre.

Snyder, C. R., Irving, L. M. \& Anderson, J. R. (1991). "Hope and health". In: Snyder, C. R. and Forsyth. D. R. (Org.). Handbook of social and clinical psychology: the health perspective. Elmsford: Pergamonm.

Tato, L. B. (2008). "El factor emocional en auditoría", Auditoría pública: revista de los Organos Autónomos de Control Externo, (44), 37-45.

Torres, J. M. B. C. R. (2010). "Qualidade de vida no trabalho (QVT) e intenção de turnover: efeito preditor de dimensões de QVT na intenção de turnover". Dissertação (Mestrado). Faculdade de Psicologia, Universidade de Lisboa, Lisboa, Portugal.

Vandenberg, R. J. \& Nelson, J. B. (1999). "Desegregating the Motives Underlying Turnover Intentions: When do Intentions Predict Turnover Behavior?", Human Relations, 52(10), 1313-1336. DOI:10.1023/A:1016964515185. 
Wubin, S. \& Zhao Liang, Y. (2010). "Main effect and moderating effect of psychological capital in the model of employee turnover intention". In: International Conference on Advanced Management Science. Disponível em: http://ieeexplore.ieee.org/document/5553049/.

Yin-Fah, B. C., Foon Y. S., Chee-Leong L. \& Osman S. (2010). "An exploratory study on turnover intention among private sector", International Journal of Business and Management, 5(8), 57-64. DOI:10.5539/ijbm.v5n8p57.

Yuen, D. C., Law, P. K., Lu, C., \& Guan, J. Q. (2013). "Dysfunctional auditing behaviour: empirical evidence on auditors' behaviour in Macau". International Journal of Accounting \& Information Management, $21(3)$, 209-226. DOI:10.1 108/IJAIM-12-2012-0075.

Zhen, Y. Mansor, Z. D. (2020). A Review on Employee's Voluntary Turnover: A Psychological Perspective, J. Mgt. Mkt. Review, 5(2) 107-112. DOI:10.37200/IJPR/V24I3/PR200978. 


\section{ANEXO}

\section{CAPITAL PSICOLÓGICO E ROTATIVIDADE DE AUDITORES INDEPENDENTES}

Prezado(a) Auditor(a)

Esse questionário tem por objetivo verificar a relação do capital psicológico no trabalho com a intenção de rotatividade dos auditores independentes. 0 questionário é composto de apenas três Seções. A Seção 1 apresenta perguntas em relação ao perfil do respondente, a Seção 2 perguntas sobre o Capital Psicológico no Trabalho e a Seção 3 busca a Intenção de Rotatividade. Você participará da pesquisa somente como respondente do questionário e, em nenhum momento ocorrerá a sua identificação. Para que possamos viabilizar nossa pesquisa, é fundamental sua participação. Sua contribuição será de grande valia.

\section{Desde já agradecemos a sua participação!!}

\section{BLOCO I - Perfil do Respondente}

Idade

De 20 a 29 anos

De 30 a 39 anos

De 40 a 49 anos

Acima de 50 anos

\section{Gênero}

$(F)$ ou (M)

\section{Tempo de experiência em auditoria}

De 0 a 4 anos

De 4,1 a 8 anos

De 8,1 a 12 anos

Acima de 12 anos

\section{Cargo que ocupa na Firma de Auditoria}

(resposta curta) 


\section{BLOCO II - Capital Psicológico no Trabalho}

Indique nas frases a seguir, o quanto você concorda ou discorda.

\begin{tabular}{|c|c|c|c|c|}
\hline $\begin{array}{c}\text { Discordo } \\
\text { Totalmente }\end{array}$ & Discordo & $\begin{array}{c}\text { Nem concordo, } \\
\text { nem discordo }\end{array}$ & $\begin{array}{c}4 \\
\text { Concordo }\end{array}$ & $\begin{array}{c}3 \\
\text { Concorda } \\
\text { totalmente }\end{array}$ \\
\hline
\end{tabular}

1. Sou capaz de resolver problemas no meu trabalho.

2. Eu espero ter conhecimento suficiente para crescer no trabalho. ()

3. Eu posso encontrar muitas maneiras de realizar meus sonhos no trabalho. ${ }^{\circledR}$

4. Fico mais forte após enfrentar demissão no trabalho.

5. Sou capaz de cumprir as obrigações do meu trabalho.

6. Eu acredito que tudo dará certo comigo no meu trabalho.

7. Fico mais forte após enfrentar mudanças no trabalho.

8. Eu espero ter energia suficiente para ser bem-sucedido no trabalho.

9. Sou capaz de dominar a tecnologia do meu trabalho. ${ }^{\circledR}$

10. Fico mais forte após enfrentar desafios no trabalho.

11. Eu acredito que dias melhores virão no meu trabalho. (

12. Fico mais forte após enfrentar perdas no trabalho. ()

13. Eu espero ter experiência suficiente para me sair bem no trabalho. ${ }^{\circledR}$

14. Eu posso achar formas para mostrar ao meu chefe que faço bem feito o meu trabalho.

15. Fico mais forte após enfrentar dificuldades no trabalho.

16. Sou capaz de dominar os procedimentos novos que surgem no meu trabalho. (B)

17. Eu acredito que coisas boas acontecerão comigo no meu trabalho. ${ }^{\circledR}$

18. Eu espero ter planos para meu futuro no trabalho.

19. Eu posso descobrir caminhos para atingir meus objetivos no trabalho.

20. Sou capaz de realizar tarefas complexas no meu trabalho. (

21. Eu posso pensar em muitas maneiras de resolver um problema no trabalho.

22. Fico mais forte após enfrentar intrigas no trabalho. ${ }^{\circledR}$

23. Sou capaz de ser criativo no meu trabalho.

24. Eu acredito que o amanhã será melhor no meu trabalho. (

25. Fico mais forte após enfrentar inveja no trabalho. ${ }^{\circledR}$

(B) Itens que compõem a versão do ICPT-12.

\section{BLOCO III - Intenção de Rotatividade}

Dê suas respostas sobre a intenção de rotatividade, considerando a seguinte escala.

\begin{tabular}{|c|c|c|c|c|}
\hline 1 & 2 & 3 & 4 & 3 \\
Nunca & Raramente & Às vezes & Frequentemente & $\begin{array}{c}3 \\
\text { Sempre }\end{array}$ \\
\hline
\end{tabular}

1. Penso em sair da empresa onde trabalho

2. Planejo sair da empresa onde trabalho

3. Tenho vontade de sair da empresa onde trabalho

( ) Eu aceito e permito que estes dados sejam utilizados para análise do artigo, ficando assegurado meu anonimato.

( ) Eu não aceito e não permito que estes dados sejam utilizados para análise do artigo. 


\section{CONTRIBUIÇÕES DOS AUTORES}

\begin{tabular}{|l|c|c|c|}
\hline \multicolumn{1}{|c|}{ Contribuição } & Mara Vogt & $\begin{array}{c}\text { Cleyson } \\
\text { Marcos }\end{array}$ & $\begin{array}{c}\text { Paulo Roberto } \\
\text { da Cunha }\end{array}$ \\
\hline $\begin{array}{l}\text { 1. Idealização e concepção do assunto } \\
\text { e tema da pesquisa }\end{array}$ & $\checkmark$ & $\checkmark$ & $\checkmark$ \\
\hline 2. Definição do problema de pesquisa & $\checkmark$ & $\checkmark$ & $\checkmark$ \\
\hline $\begin{array}{l}\text { 3. Desenvolvimento da Plataforma } \\
\text { Teórica }\end{array}$ & $\checkmark$ & $\checkmark$ & \\
\hline $\begin{array}{l}\text { 4. Delineamento da abordagem } \\
\text { metodológica da pesquisa }\end{array}$ & $\checkmark$ & & \\
\hline 5. Coleta de dados & $\checkmark$ & & \\
\hline $\begin{array}{l}\text { 6. Análises e interpretações dos dados } \\
\text { coletados }\end{array}$ & $\checkmark$ & & \\
\hline 7. Conclusões da pesquisa & $\checkmark$ & & $\checkmark$ \\
\hline $\begin{array}{l}\text { 8. Revisão crítica do manuscrito } \\
\text { 9. Redação final do manuscrito, } \\
\text { conforme as normas estabelecidas pela } \\
\text { Revista. }\end{array}$ & $\checkmark$ & & \\
\hline 10. Orientação & & & \\
\hline
\end{tabular}

